\title{
Mussel inspired green synthesis of silver nanoparticles-decorated halloysite nanotube using dopamine: characterization and evaluation of its catalytic activity
}

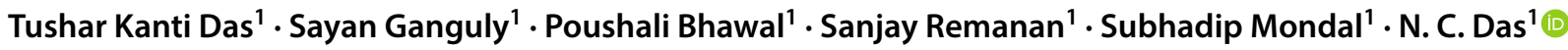

Received: 26 September 2017 / Accepted: 15 November 2017 / Published online: 31 January 2018

(c) Springer-Verlag GmbH Germany, part of Springer Nature 2018

\begin{abstract}
Naturally occurring ceramic tubular clay, Halloysite nanotubes (HNTs), having a significant amount of surface hydroxyls has been coated by self-polymerized dopamine in this work. The polydopamine-coated HNTs acts as a self-reducing agent for $\mathrm{Ag}^{+}$ion to $\mathrm{Ag}^{0}$ in nanometer abundance. Herein, nano size $\mathrm{Ag}^{0}$ deposited on solid support catalyst has been used to mitigate water pollution within $10 \mathrm{~min}$. To establish the versatility of the catalyst, nitroaryl (4-nitrophenol) and synthetic dye (methylene blue) have been chosen as model pollutant. The degradation/reduction of the aforementioned pollutants was confirmed after taking UV-visible spectra of the respective compounds. All the study can make sure that the catalyst is green and the rate constant value for catalytic reduction of 4-nitrophenol and methylene blue was calculated to be $4.45 \times 10^{-3}$ and $1.13 \times 10^{-3} \mathrm{~s}^{-1}$, respectively, which is found to be more efficient in comparison to other nanostructure and commercial $\mathrm{Pt} / \mathrm{C}$ nanocatalyst $\left(1.00 \times 10^{-3} \mathrm{~s}^{-1}\right)$.
\end{abstract}

Keywords Halloysite nanotubes · Dopamine $\cdot$ Polydopamine $\cdot$ Catalyst $\cdot$ 4-Nitrophenol $\cdot$ Methylene blue

\section{Introduction}

Recently, applications of organic pollutants, such as dyes and derivatives of phenol, are escalated due to extensive use in various field such textile, paper, leather industries and the uncontrolled discharge of these organic pollutants into main stream water leads to environmental hazardousness which in turn affects the aquatic life as well as unsuitable esthetic facet (Almeida et al. 2009; Choudhary et al. 2017; El Qada et al. 2008; Küncek and Şener 2010; Venkatesham et al. 2014). Moreover, the presence of the organic dyes in the ground water is unsuitable for irrigation and drinking. So elimination of these organic pollutants from wastewater has been now gained attention towards researchers. Basically, the dyes and phenol derivatives chemically contain

Electronic supplementary material The online version of this article (https://doi.org/10.1007/s13204-018-0658-3) contains supplementary material, which is available to authorized users.

N. C. Das

ncdas@rtc.iitkgp.ernet.in

1 Rubber Technology Center, Indian Institute of Technology Kharagpur, Kharagpur, India a wide range of chemical structures, mainly based on the aromatic groups with substitutions. Due to this complexity in its structure, it is very difficult to degrade by physical, chemical or biological treatments (Forgacs et al. 2004; Zhao and Liu 2008). Already various conventional methods such as biological treatment, flocculation, coagulation, chemical oxidation, adsorption, and ozone treatment have been adopted for treatment of wastewater to degrade pollutant (Gong et al. 2009). Biological treatment of industrial wastewater leads to the formation of toxic material which is resistant to degrade by biological treatment. Therefore, the separations of these toxic materials require additional cost (GarcíaMontaño et al. 2006). On the other hand, the major disadvantage of flocculation and coagulation process is the production of high amount of sludge and further chemical treatment is needed to reduce sludge (Golob et al. 2005). Wastewater treatments by ozonization generate sometimes carcinogenic small molecules which require simultaneously a physical method to prohibit this (Robinson et al. 2001). Whereas in case of adsorption process, extra charges deal with removal of pollutants from the surface adsorbent and treatments of the surface is prerequisite for the next cycles (Crini 2005). Only single chemical oxidation process is not sufficient to decompose organic pollutant completely. 
Therefore, after oxidation another treatment of pollutants is required for complete destruction (Gupta et al. 2012). So, these methods are considered as ineffective degradation for further treatments, which results in additional costs and makes the process more expensive. But the latest developed nanocatalyst decomposes the wastewater pollutants in such a way that it neither requires extra cost for further treatment nor produces toxic materials that can affect living organism. Hence, it is very crucial for choosing a method to ascertain an efficient eco-friendly way of pollutants treatment to protect our environment.

Recently, few studies reported on the novel metal nanoparticles as convincible catalyst for degradation of such pollutants in the presence of visible light under normal atmospheric condition (Mohamed et al. 2012; Raza et al. 2017). Degradation of this type of complex pollutant structure can be accomplished by increment of optical path length of photons commanding towards higher absorption rate under localized electrical field (García 2011). Nanoparticles showed unique morphology and improve properties, which are completely different from their bulk structure (Gurunathan et al. 2009). Hence, researchers have shown ample importance in using nanoparticles for catalytic degradation of dyes and phenol derivatives.

Halloysite nanotubes (HNTs), $\left[\mathrm{Al}_{2} \mathrm{Si}_{2} \mathrm{O}_{5}(\mathrm{OH})_{4} \cdot 2 \mathrm{H}_{2} \mathrm{O}\right]$ naturally abundant eco-friendly and biocompatible kaolinite clay family, belong to hollow tube-like structure (Zhang et al. 2013). Layer of abundant aluminum and silicate at a ratio of 1:1 is the primary constituent of HNTs and surface $-\mathrm{OH}$ groups attach to aluminum and silicon making HNTs strongly hydrophilic (as shown in Fig. 1) which also provides further modification to perform through these groups (Hebbar et al. 2016). In comparison to other nanomaterials like carbon nanotubes (CNT), boron nitride tube, etc., HNTs are much inexpensive and easily accessible. Hence, currently researchers are trying to explore HNTs as nano-template in place of CNT-like expensive materials.

Stimulating by gumminess characteristic of 3,4-dihydroxy-L-phenylalaine (commonly known dopamine), which is found lavishly in mussel foot proteins (Lee et al. 2007) and its polymer, poly-dopamine (PDA) have been comprehensively used in diverse range of application such as surface modification, metallization from its ionic state, protein immobilization, biomineralization, cell adhesion, drug delivery etc. (Ganguly et al. 2016; Kang et al. 2010; Ku et al. 2010; Lee et al. 2011, 2009; Liu et al. 2012). PDA is prepared by simple oxidative polymerization of dopamine in the presence of aqueous alkaline solution. Though accurate chemical structure of PDA is still unknown, there is an agreement that it is composed of various states of hydrogenated indole units connected by $\mathrm{C}-\mathrm{C}$ bond in between benzene rings (Liu et al. 2014). The coating of PDA can not only strenuously adhere on the surface of organic or inorganic surface through polymerization of dopamine but also from environmental point of view it is non-toxic and biocompatible (Lynge et al. 2015).

Herein, we report a facile and green approach to prepare HNTs-supported AgNPs composites using bio-inspired in situ oxidative polymerization of dopamine for highly efficient and reusable catalytic reduction of toxic 4-nitrophenol

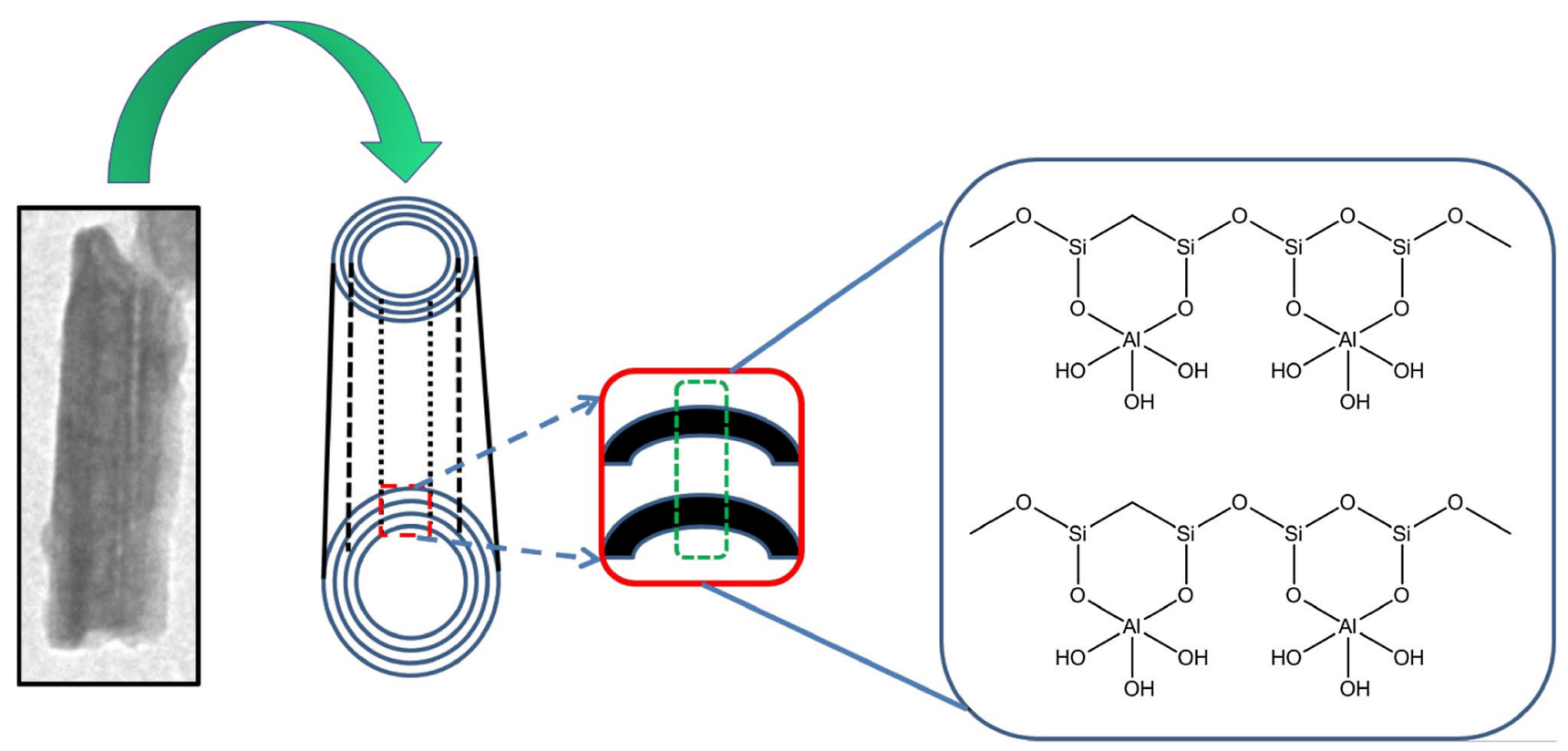

Fig. 1 Chemical structure of cross-section of halloysite nanotube 
(4-NP) and degradation methylene blue (MB). HNTs are firstly modified by PDA coating and then AgNPs are decorated on the surface of HNTs via adsorption of silver nitrate $\left(\mathrm{AgNO}_{3}\right)$ and simultaneously in situ reduction by mussel inspired PDA. Here, PDA coating not only serves the purpose of reduction but also acts as a stabilizer for the deposited nanoparticles over HNTs surface. AgNPs-decorated HNTs catalysts exhibit an efficient catalytic performance towards reduction of 4-NP as well as degradation of methylene blue in the presence of sodium borohydride. Anchored AgNPs are so tightly bound on the surface of HNTs that the catalyst shows almost same performance after several cycles. This highly active and recyclable catalyst would endorse as heterogeneous catalytic application, purification of water and other separation and purification fields of green chemistry.

\section{Experimental}

\section{Materials}

HNTs having surface area $65 \mathrm{~m}^{2} \mathrm{gm}^{-1}$, dopamine hydrochloride ( $\geq 98 \%$ pure), tris (hydroxyl methyl) amino methane (Tris base, $\geq 99 \%$ pure), silver nitrate (ACS reagent $\geq 99 \%$ pure), 4-nitrophenol ( $\geq 99 \%$ pure), and sodium borohydride (ACS reagent, $\geq 98 \%$ pure) were obtained from SigmaAldrich and used without further purification. Methylene blue was purchased from Loba-Chemie and used as received. For all experimental studies, distilled water was used.

\section{Synthesis of PDA-coated halloysite nanotubes (HNTM)}

PDA-coated HNTs were prepared in the following procedure: $300 \mathrm{mg}$ of HNTs was dispersed by sonication in
$100 \mathrm{ml}$ water to obtain HNTs suspension. After half an hour sonication, the $\mathrm{pH}$ of the suspension was adjusted to 8.5 by adding Tris- $\mathrm{HCl}$ base $(10 \mathrm{mM}$ solution maintained at $\mathrm{pH}$ 8.5). Subsequently, $50 \mathrm{mg}$ of dopamine hydrochloride (DOPA) powder was added on to HNTs suspension and stirred for next $6 \mathrm{~h}$ maintaining temperature at $30^{\circ} \mathrm{C}$. As the reaction time progresses, the white color HNTs dispersion was changed to black color insoluble PDA-coated HNTs as shown in Fig. 2. The black color product was recovered from final mixture by centrifugation and followed by thoroughly washing with distilled water until the filtrate became colorless. Finally, solid black color product was obtained after drying at $60{ }^{\circ} \mathrm{C}$ under reduced pressure for $24 \mathrm{~h}$ in vacuum drying oven.

\section{Synthesis of AgNPs-decorated PDA-coated halloysite (HNTAgX) nanocomposite}

For synthesis of AgNPs-decorated HNTs, different concentration of silver nitrate solution was prepared in $20 \mathrm{ml}$ water. After that $100 \mathrm{mg}$ of PDA-HNTs samples was separately dispersed in $80 \mathrm{ml}$ of distilled water using a bath-sonicator for half an hour. Then, to each dispersed solution $20 \mathrm{ml}$ of different concentrated silver nitrate solution was added to maintain 1,2, 3, 4, 5 and $6 \mathrm{mM}$ silver nitrate conc. in the final solution and immediately the mixture was stirred for $24 \mathrm{~h}$ at $30^{\circ} \mathrm{C}$. The synthesized products are denoted by HNTAgX where X stands for conc. of silver nitrate. Later, gray color AgNPs-decorated HNTs product (shown in the Fig. 2) was obtained by centrifugation and washing repeatedly with water to remove unreacted silver nitrate. Lastly, the centrifuged products were dried at $60{ }^{\circ} \mathrm{C}$ under reduced pressure for $24 \mathrm{~h}$ in drying oven to get AgNPs-decorated HNTs. To study the optimum rate constant for catalytic reduction of 4-NP in the presence of $\mathrm{NaBH}_{4}$, we prepared

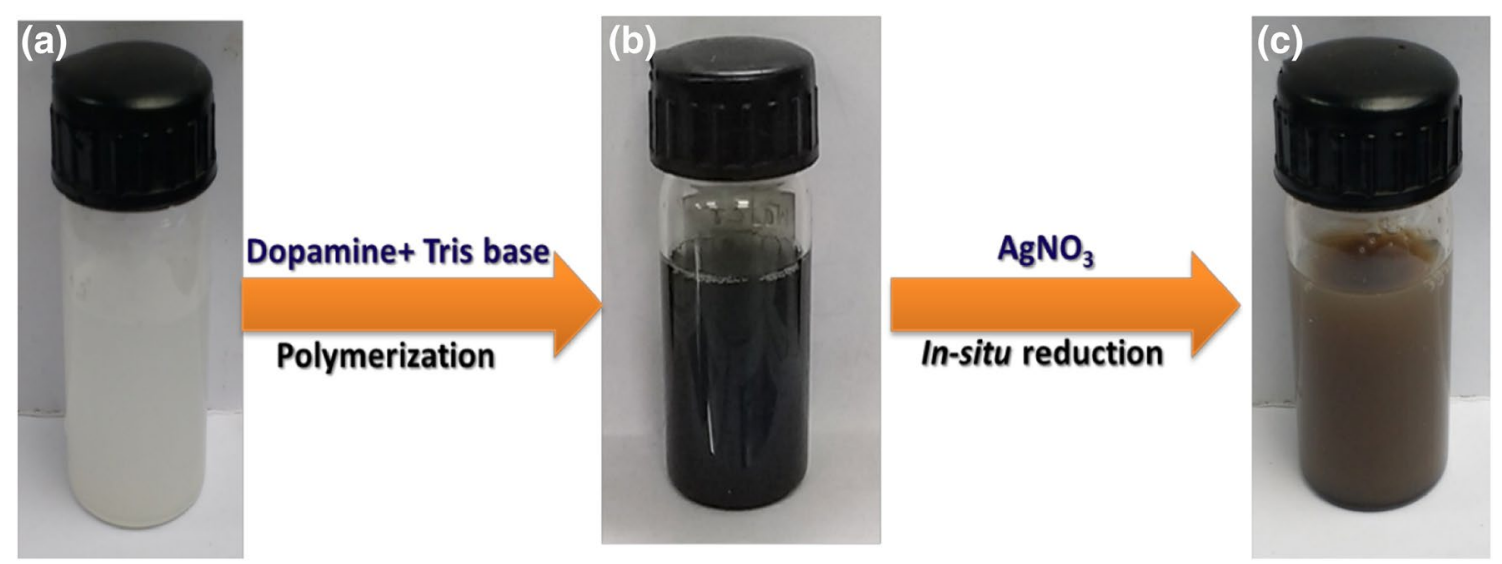

Fig. 2 Digital image of aqueous dispersion of a pure HNTs, b HNTM and c HNTAgX 
another three HNTAgX nanocomposites based on 4, 5, and $6 \mathrm{mM}$ silver nitrate conc.

\section{Catalytic study of $p$-nitrophenol (4-NP) reduction and methylene blue (MB) degradation}

Catalytic activities of the synthesized nanocomposites were evaluated using reduction of 4-NP and degradation of $\mathrm{MB}$ in the presence of $\mathrm{NaBH}_{4}$ as model catalytic study for reduction of nitrophenol derivatives and degradation of synthetic dye, respectively. Aqueous solution of 4-NP (20 ml, $1 \mathrm{mM}$ ) was stirred with freshly prepared $\mathrm{NaBH}_{4}$ $(3 \mathrm{ml}, 0.2 \mathrm{M})$. After that, immediately $1 \mathrm{~g}$ of synthesized catalyst was added to the mixture. Subsequently, in each 1-min interval aliquot was withdrawn from the reaction mixture and UV-vis absorption spectra was recorded to monitor the reduction process of 4-NP. The stability of the catalysts was evaluated by repeating the same reduction process for six numbers of cycles with same catalyst. After each catalytic conversion, catalysts were separated from the reaction mixture by centrifugation and followed by repeatedly washing with distilled water and ethanol for next cycle. In the study of catalytic MB degradation, the same procedure as stated above was followed where aqueous solution of MB (50 ml, $3 \mathrm{gm} / \mathrm{l})$ was stirred with freshly prepared $\mathrm{NaBH}_{4}(10 \mathrm{ml}, 0.2 \mathrm{mM})$ and $5 \mathrm{mg}$ of nanocomposites sample was used.

\section{Characterization technique}

The alteration of microstructural changes of HNTs and its modified samples were resolute by Fourier transform infrared spectroscopy (FT-IR, model spectrum-2, Singapore) using KBR pellets with scanning range $600-4000 \mathrm{~cm}^{-1}$ and resolution $4 \mathrm{~cm}^{-1}$. To examine the crystalline structure of the prepared samples, X-Ray diffraction (XRD, X Pert PRO manufactured by PAN analytical B.V. Netherlands) was performed using Ni-filtered $\mathrm{Cu} \mathrm{K} \alpha(\lambda=1.534 \AA)$ radiation source with rate of scanning $0.005^{\circ}(2 \theta / \mathrm{s})$ from $5^{\circ}$ to $80^{\circ}$. High-resolution transmission electron microscopy (HRTEM, JEM-2100, JEOL, Japan accelerated voltage $200 \mathrm{kV}$ ) and FESEM (Field emission scanning electron microscope, MERELIN with tungsten; Carl ZESISS, SMT, Germany, stimulating voltage set to $15 \mathrm{kV}$ ) were carried out to analyze morphology of the prepared samples. For quantitative determination of elements present in the synthesized material, during FESEM analysis energy dispersive X-ray spectroscopy (EDX) was recorded and evaluated using Oxford X-max detector. The diameter of Ag nanoparticles was resolute by IMAGE J software using FESEM image. Spectra of water dispersed HNTs, HNTM and HNTAgX samples and monitoring data of catalytic reduction of 4-NP to 4-aminophenol (4-AP) by HNTAgX samples were documented by UV-Visible spectrophotometer (UV-1601, Shimadzu, Japan).

\section{Results and discussion}

\section{Morphological properties}

Though previously modifications of HNTs have been already explored but the process through which modification has been done either under strident condition or with assorted stages (Mu et al. 2013; Zhang and Yang 2012). In our study, catalytic AgNPs-decorated HNTs nanocomposites were fabricated via simple two-step process. In 1st step negatively charged PDA was used to coat the surface of positively charged HNTs in Tris buffer solution where dopamine can be spontaneously polymerized to PDA and adhere to the HNTs surface. In the next step, positively charged amine groups of PDA make a complex with $\mathrm{AgNO}_{3}$ which will be instinctively reduced to metallic silver nanoparticles resulting in situ generation of AgNPs on the surface of PDA modified HNTs. Basically, PDA layers act as a reducing agent as well as provide stabilization for AgNPs on an inexpensive, naturally occurring HNTs support.

The morphology and length of HNTs were investigated through FESEM image as shown in Fig. 3. HNTs exhibited open-ended rod-like structure having more or less uniform width about $100 \mathrm{~nm}$. The distribution of lengths obtained from FESEM image of HNTs was measured statically and its histogram is represented in Fig. 4a. As HNTs are naturally occurring substances, the length of nanotubes (here HNTs) lies in a wide range of length distribution. The lengths of HNTs were varied from 200 to $1300 \mathrm{~nm}$ maintaining the characteristic of polydispersity which is a common and trustworthy fact reported (Pasbakhsh et al. 2013; Zhai et al. 2010). Fig. 3b shows FESEM image of HNTs after surface coated with oxidative polymerized dopamine. It is clearly demonstrated that those nanotubes which have a tendency to form agglomerate along its axis are likely to be isolated from each other. This may be due to HNTs coated with negatively charged PDA which repels each other. Furthermore, in Fig. 3c, a lot of isolated and randomly distributed white spots were clearly observed on the nanotube surface. This white spot indicates the presence of AgNPs which were reduced by PDA and deposited on the HNTs surface. The diameter of AgNPs was measured from Fig. 3c by Image $\mathbf{J}$ software and the corresponding histogram is represented in Fig. 4b. The average diameter of AgNPs after fitting with Gaussian distribution curve was found to be $9.06 \pm 1.987 \mathrm{~nm}$. 

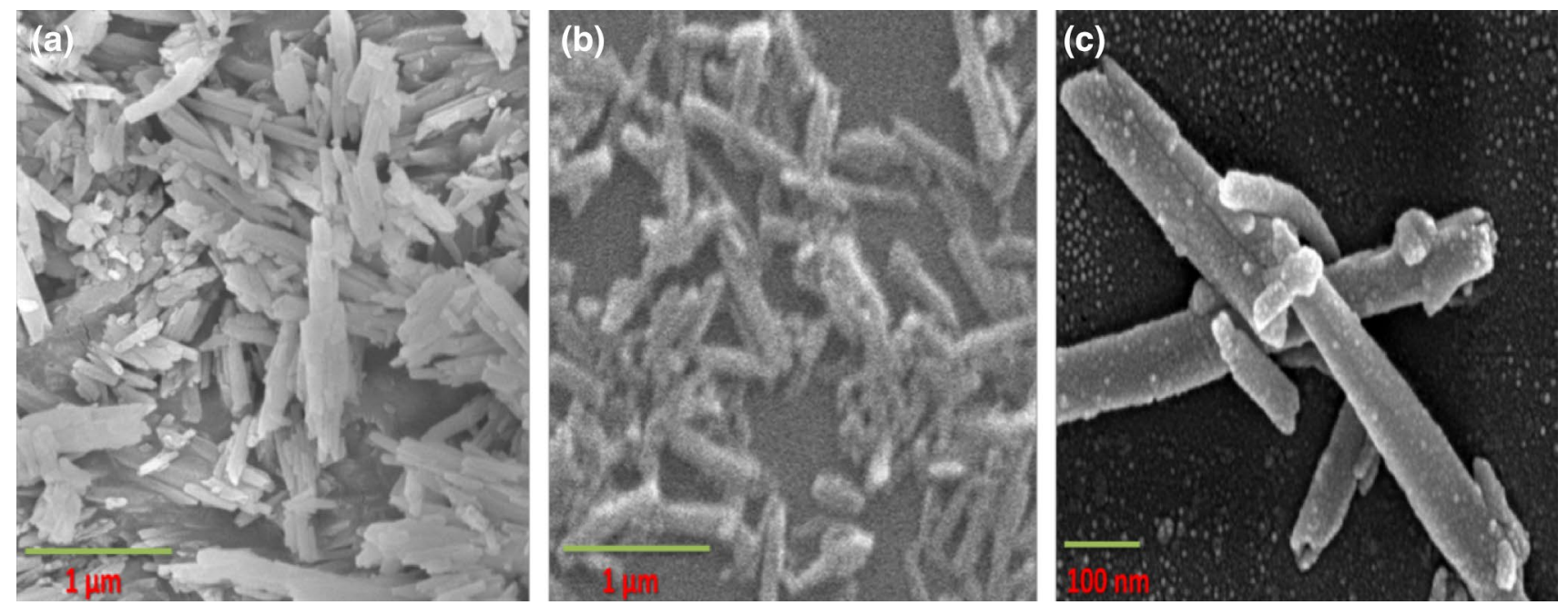

Fig. 3 FESEM image of a pure HNTs, b PDA-coated HNTs (HNTM) and $\mathbf{c}$ HNTAgX nanocomposites
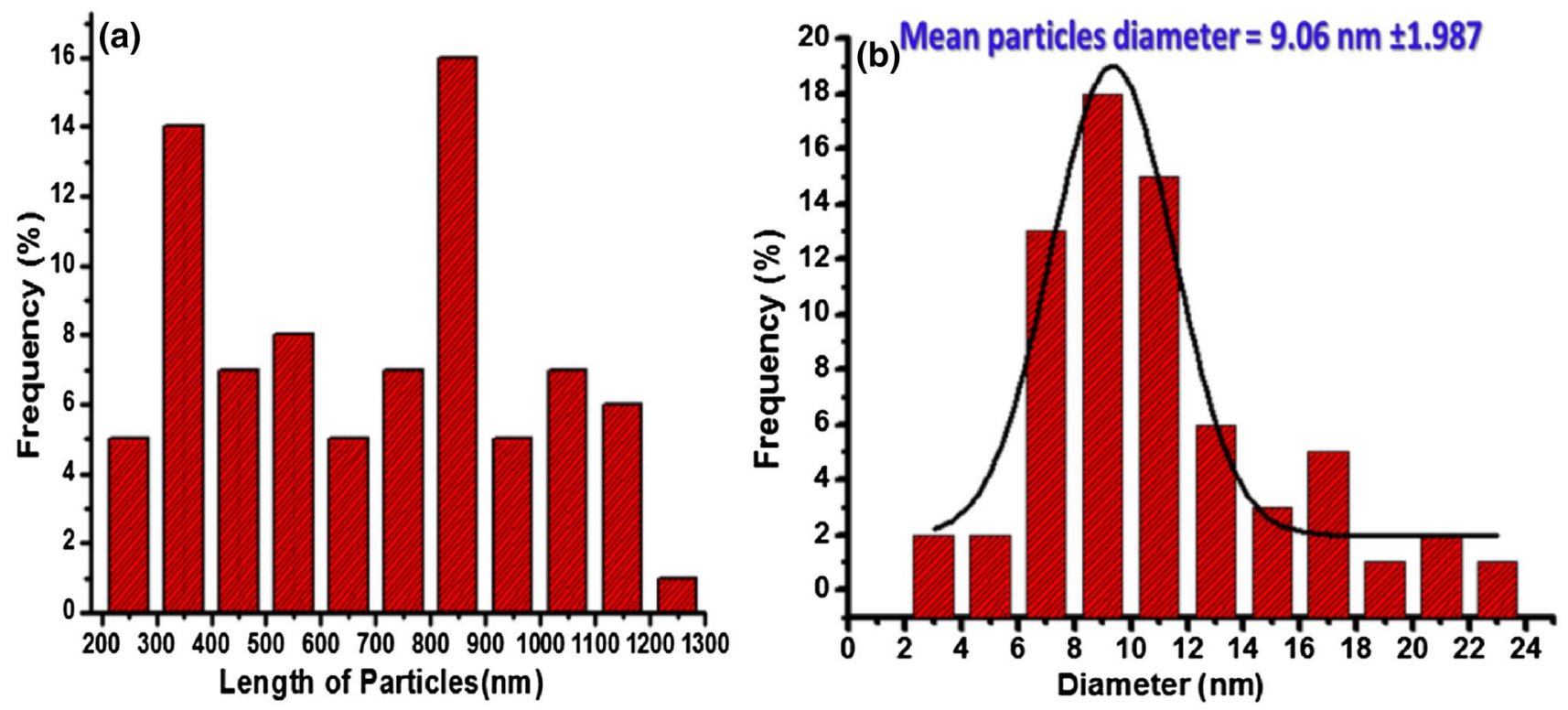

Fig. 4 a Histogram of length distribution of HNTs and b particle size distribution of AgNPs obtained from FESEM image of Fig. 3a, c, respectively

The elemental analysis of HNTs and HNTM was performed by energy dispersive X-ray spectrum (EDX) which shows that HNTs are composed of $\mathrm{Al}, \mathrm{Si}$ and $\mathrm{O}$ (shown in Fig. 5a), whereas HNTM is belonged to $\mathrm{Al}, \mathrm{Si}, \mathrm{O}$ and $\mathrm{C}$ (shown in Fig. 5b). Addition of $\mathrm{C}$ as element in HNTM appeared from the contribution of PDA indicating successful attachment of PDA on the surface of HNTs. To ratify the successful formation of HNTAgX nanocomposites along with FESEM, EDX of constitute elements was also recorded and represented in Fig. 5c. It clearly shows that the intensity of $\mathrm{Si}$ and $\mathrm{Al}$ is very high in comparison to
Ag indicating small amount of AgNPs distributed over the circumference of nanotubes. EDX analysis also revealed that the presence of carbon and high intensity oxygen peak (contribution of both PDA and HNTs) signifies a successful coating of PDA over HNTs.

Figure 6 represents TEM images of HNTs, HNTM and HNTAgX. TEM image of HNTs (Fig. 6a) revealed that the halloysite samples exhibit open-ended hollow cylindrical geometry. The length of the tube is around $400 \mathrm{~nm}$ and the diameter is in the range of $50 \mathrm{~nm}$. After modification with dopamine, HNTM showed increase 

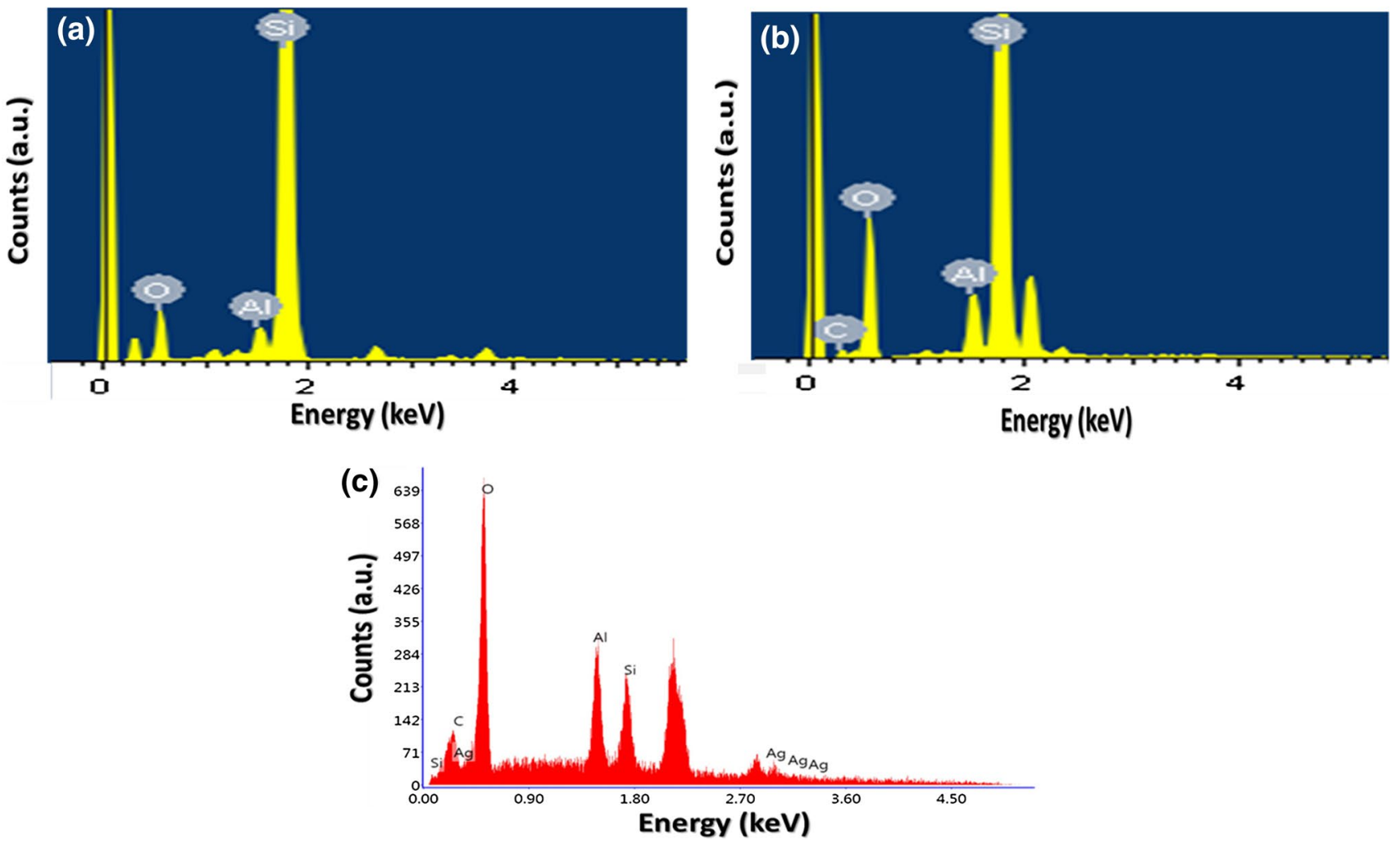

Fig. 5 EDX spectrum of a pure HNTs, b HNTs modified with PDA and $\mathbf{c}$ HNTAgX nanocomposite
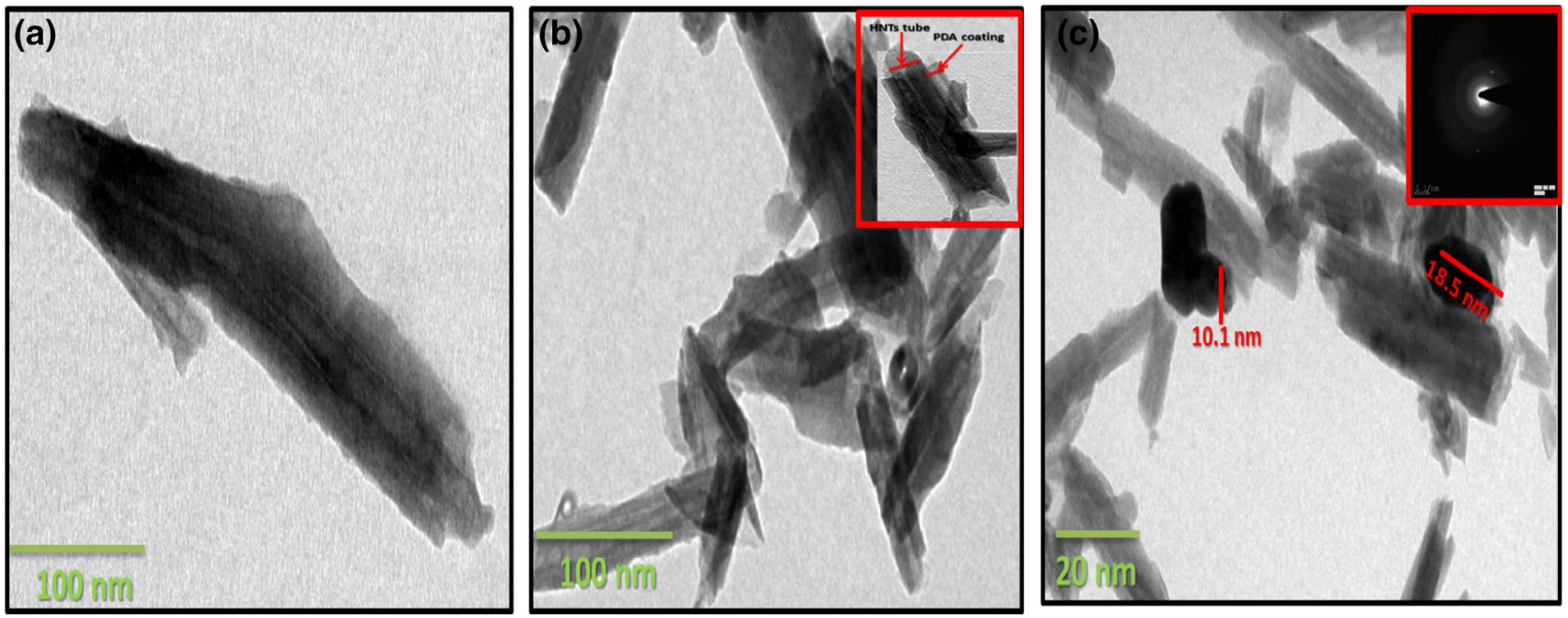

Fig. 6 TEM images of a pure HNTs, b PDA-coated HNTs (HNTM) and $\mathbf{c}$ HNTAgX nanocomposite. The inset of b shows distinct thin layer polydopamine coating of about $\sim 20 \mathrm{~nm}$ thickness upon HNTs and the inset of c represents SAED pattern of HNTAgX nanocomposite

wall thickness (Fig. 6b) indicating successful coating of HNTs by polymerization of dopamine. The inset of this Fig. $6 \mathrm{~b}$ clearly exhibits distinct coating of PDA layers on the surface of HNTs. The increase in wall thickness is found to be $\approx 20 \mathrm{~nm}$ (measured by IMAGE J software). Figure $6 \mathrm{c}$ of HNTAgX clearly represents that black spots of spherical shape AgNPs, having diameter in the range of 10-20 nm, were attached to the surface of cylindricalshaped HNTs. The inset of Fig. 6c exhibits selected area electron diffraction (SAED) pattern of HNTAgX nanocomposite. The ring-shaped diffraction pattern implies that the particles present in the nanocomposites are 


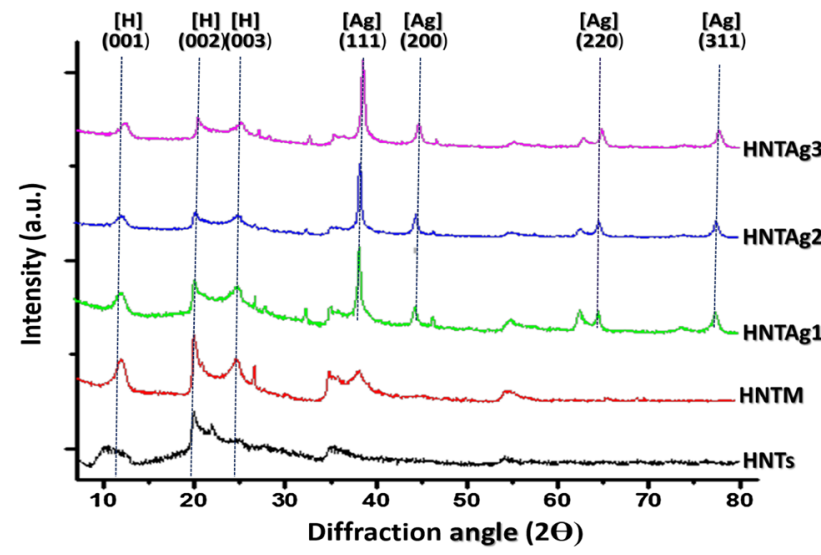

Fig. 7 XRD pattern of pure HNTs, PDA-coated HNTs (HNTM) and various concentration AgNPs loaded HNTAgX nanocomposites

polycrystalline in nature (Annamalai and Nallamuthu 2016; Liu et al. 2010).

\section{XRD pattern}

X-ray diffraction pattern of HNTs, MHNT and HNTAgX is represented in Fig. 7. For HNTs sample, all noticeable peaks are very much close to the characteristic peak of halloysite (JCPDS No. 29-1487) (Zhong et al. 2014). After modification with polydopamine (PDA), there is no observable change indicating that coating with PDA does not affect the crystalline structure HNTs. XRD pattern of all HNTAgX samples exhibits distinct peak at $2 \theta=38.4^{\circ}, 44.5^{\circ}, 64.7$ and 77.7 along with characteristic HNTs peaks. The added peak positions can be harmonized with (111), (200), (220) and (311) planes of face-center cubic silver nanoparticle (JCPDS No.04-0783) (Ganguly et al. 2017; Zia et al. 2016). The full width at half maximum (FWHM) values was calculated for both HNTs and AgNPs from their corresponding broadness (001) and (111) reflection plane, respectively. Later, well-known Debye-Scherrer equation was used to measure crystallite sizes (Holzwarth and Gibson 2011). The mean crystallite size of HNTs and AgNPs was found to be 50 and $12.26 \mathrm{~nm}$, respectively. The size obtained from broadening of XRD peaks was well consistent with results obtained from FESEM and TEM results. It suggested that silver nanoparticles were successfully synthesized by PDA on the surface of HNTs (Liu et al. 2010).

\section{FT-IR studies}

FT-IR spectra of HNTs and HNTM were accomplished and represented in Fig. 8. From the figure, it is clearly noticed that HNTs exhibit strong absorption peak at $905 \mathrm{~cm}^{-1}$ due to the presence of $\mathrm{Al}-\mathrm{OH}$ groups. The peak at 3692 and $3625 \mathrm{~cm}^{-1}$ was attributed to hydroxyl groups attached to the

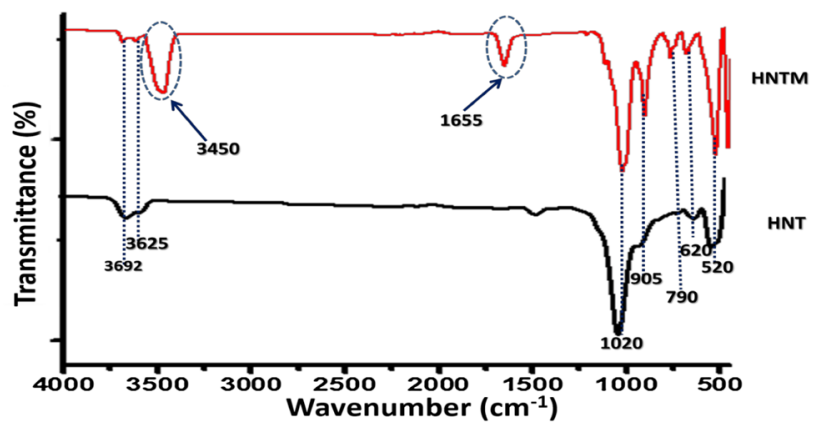

Fig. 8 FT-IR spectra of pure HNTs and PDA-coated HNTs (HNTM)

surface of HNTs molecules. Other strong peaks appearing around $1000 \mathrm{~cm}^{-1}$ and in between 800 and $500 \mathrm{~cm}^{-1}$ were corresponding to $\mathrm{Si}-\mathrm{O}$ bond stretching and bending, respectively (Krishnaiah et al. 2017). HNTM showed a broad band around $3400 \mathrm{~cm}^{-1}$ due to the stretching of $-\mathrm{NH}_{2}$ groups and another new peak appeared at $1655 \mathrm{~cm}^{-1}$ attributed to the presence of carbonyl moiety of PDA molecules. The characteristic peaks associated with HNTs remained also intact in HNTM though changes of peaks intensity may take place and small shifting of peaks signified chemical interaction between HNTs and PDA (Chao et al. 2013). These results indicate that PDA-modified HNTs (HNTM) were synthesized favorably.

\section{UV-visible absorption studies}

UV-visible absorption spectroscopic studies of water dispersed HNTs, HNTM and HNTAgX samples are represented in Fig. 9. UV-vis absorption spectra of dispersed HNTs and HNTM exhibited no characteristic absorption peak in the spectral region, while HNTAgX samples showed broad absorption band around in the range of 400 to $425 \mathrm{~nm}$. This characteristic absorption band emanated due to surface

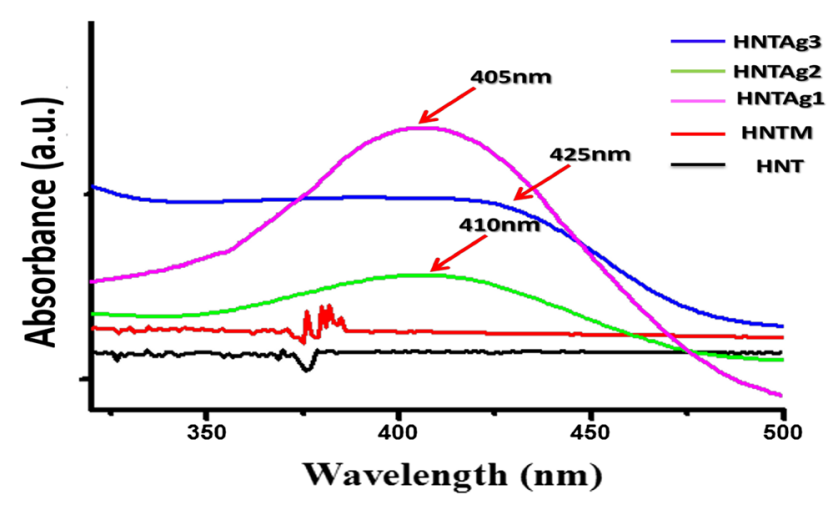

Fig. 9 UV-Visible spectra of aqueous dispersion of pure HNTs, PDAcoated HNTs (HNTM) and various concentration AgNPs-loaded HNTAgX nanocomposites 
plasma resonance (SPR) of AgNPs decorated on the surface of HNTs (Kumar-Krishnan et al. 2015).

\section{Application of synthesized catalysts}

\section{4-Nitrophenol (4-NP) reduction studies}

The catalytic activity of Ag/HNTs nanocoposites was examined by way of reduction 4-NP to 4-aminophenol in the presence of $\mathrm{NaBH}_{4}$ as a model pseudo-first-order reaction. Such type of reaction catalyzed by novel metal particles has been comprehensively reported as this reaction can be easily monitored by UV-visible spectroscopy (Das et al. 2017; Hervés et al. 2012; Hu et al. 2015; Krishna et al. 2016; Majumdar et al. 2016). Figure $S 1$ shows representative time-dependent UV-visible absorption spectra of reduction of 4-NP in the presence of $\mathrm{NaBH}_{4}$. On addition of Ag/HNTs nanocomposites to the reaction mixture, the bright yellow color of the mixture slowly changes to colorless with time as shown in Fig. 10. The characteristic UV-visible absorption peak at $400 \mathrm{~nm}$ of 4-NP in the presence of $\mathrm{NaBH}_{4}$ disappeared within $10 \mathrm{~min}$ and a new absorption peak at $300 \mathrm{~nm}$, due to the formation of 4-AP, increased as the reaction progressed with time. After $10 \mathrm{~min}$, no absorption peak at $400 \mathrm{~nm}$ is noticeable indicating almost complete reduction of 4-NP. As 200 times excess concentration of $\mathrm{NaBH}_{4}(0.2 \mathrm{M})$ was used in comparison to that of 4-NP $(1 \mathrm{mM})$, it can be assumed that the concentration of $\mathrm{NaBH}_{4}$ remained constant throughout the reduction reaction. Hence, in order to determine the rate constant of this reaction pseudo-first-order kinetic can be implemented. The pseudo-first-order kinetic equation of reduction of 4-NP could be given as follows:

$\ln \left(\frac{A_{t}}{A_{0}}\right)=-k_{\text {app }} t$

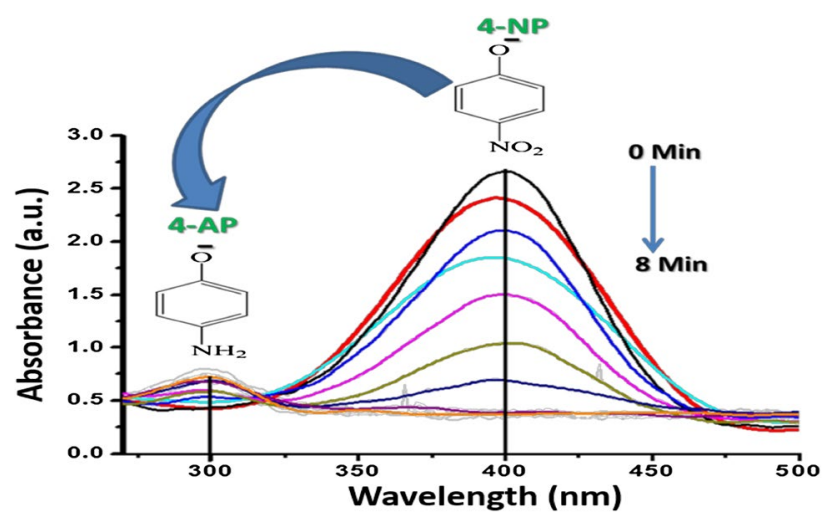

Fig. 10 Representative time-dependent UV-vis spectra of 4-NP reduction in the presence of $\mathrm{NaBH}_{4}$ by nanocomposite where $A_{t}$ and $A_{0}$ are the concentrations of 4-NP at time $t=t$ and $t=0$ obtained from intensity of absorption peak at $400 \mathrm{~nm}, k_{\text {app }}=$ apparent rate constant and $t=$ time. Exponential decay plot of $\left(A_{t} / A_{0}\right)$ versus time (as shown in Fig. 11a) indicates that the reduction reactions follow first-order reaction kinetics. A liner correlation of $\ln \left(A_{t} / A_{0}\right)$ versus time (Fig. 11c) also suggests the reduction reaction dawdles first-order reaction kinetics. The rate constants $(k)$ for reduction of 4-NP obtained from liner relation for each catalytic HNTAgX nanocomposites have been shown in Table 1.The rate constant and time required for catalytic conversion of 4-NP are higher than commercially available $\mathrm{Pt} / \mathrm{C}$ nanocatalyst (Liu et al. 2015) and previous reported results (as shown in Table 2) (Cao et al. 2017; Hareesh et al. 2016; Sahoo et al. 2014; Wang et al. 2012, 2013, 2015). To determine the ideal concentration of $\mathrm{AgNO}_{3}$ at which rate constant of catalytic reduction will be maximum, we performed the catalytic reduction of 4-NP in the presence of $\mathrm{NaBH}_{4}$ for six different HNTAgX nanocomposite. Plot of $A_{t} / A_{0}$ versus reaction time is shown in Fig. 11a. The exponential decrease of curve is faster as we shifted from HNTAg1 to HNTAg5 nanocomposite. But for HNTAg6 nanocomposite, the exponential decrease is not so significant in comparison to that of HNTAg5 nanocomposite. These two nanocomposites curves almost overlap with each other. The comparison is clearly established after liner fitting of the data (shown in Fig. 11b) and rate constant $\left(k_{\text {app }}\right)$ obtained from the slope is represented in the Table 2. Plot of rate constant versus $\mathrm{AgNO}_{3}$ concentrations is represented in Fig. 11c. It undoubtedly demonstrated that $k_{\text {app }}$ value continuously increases with incremental addition of $\mathrm{AgNO}_{3}$ up to $5 \mathrm{mM}$ (HNTAg5 nanocomposite) and after that $k_{\text {app }}$ value for $6 \mathrm{mM} \mathrm{AgNO}_{3}$ (HNTAg5 nanocomposite) decreases. But the decrease in $k_{\text {app }}$ value for $6 \mathrm{mM}$ is very small (more or less constant). Hence based on the observation, it can be implied that $5 \mathrm{mM}$ (HNTAg5 nanocomposite) is the optimum concentration of $\mathrm{AgNO}_{3}$ for catalytic reduction of 4-NP in the presence of $\mathrm{NaBH}_{4}$. The variation of rate constant of nanocomposites mainly depends on the size of the nanoparticles, amount of nanoparticles formed and aggregation of them which directly related to the synthesis parameters such as reaction time, concentration of reducing agent (here PDA), $\mathrm{pH}$ of the medium and molar ratio of reducing agent to metal salts added as precursor for nanoparticles (Wang et al. 2017). During the synthesis of AgNPs in our work, as all other synthesis parameters are kept fixed except molar ratio of reducing agent to metal salt, it can affect morphology of the synthesized AgNPs over HNTs surface. Lower amount of AgNPs is easily achievable by adding lower amount of metal salts, whereas an increasing amount of metal salts leads to the formation of aggregation(Sobczak-Kupiec et al. 2011; Zeng et al. 2013). Here in our work, the ability of PDA to reduce salt into AgNPs is feasible up to $5 \mathrm{mM}$ concentration 

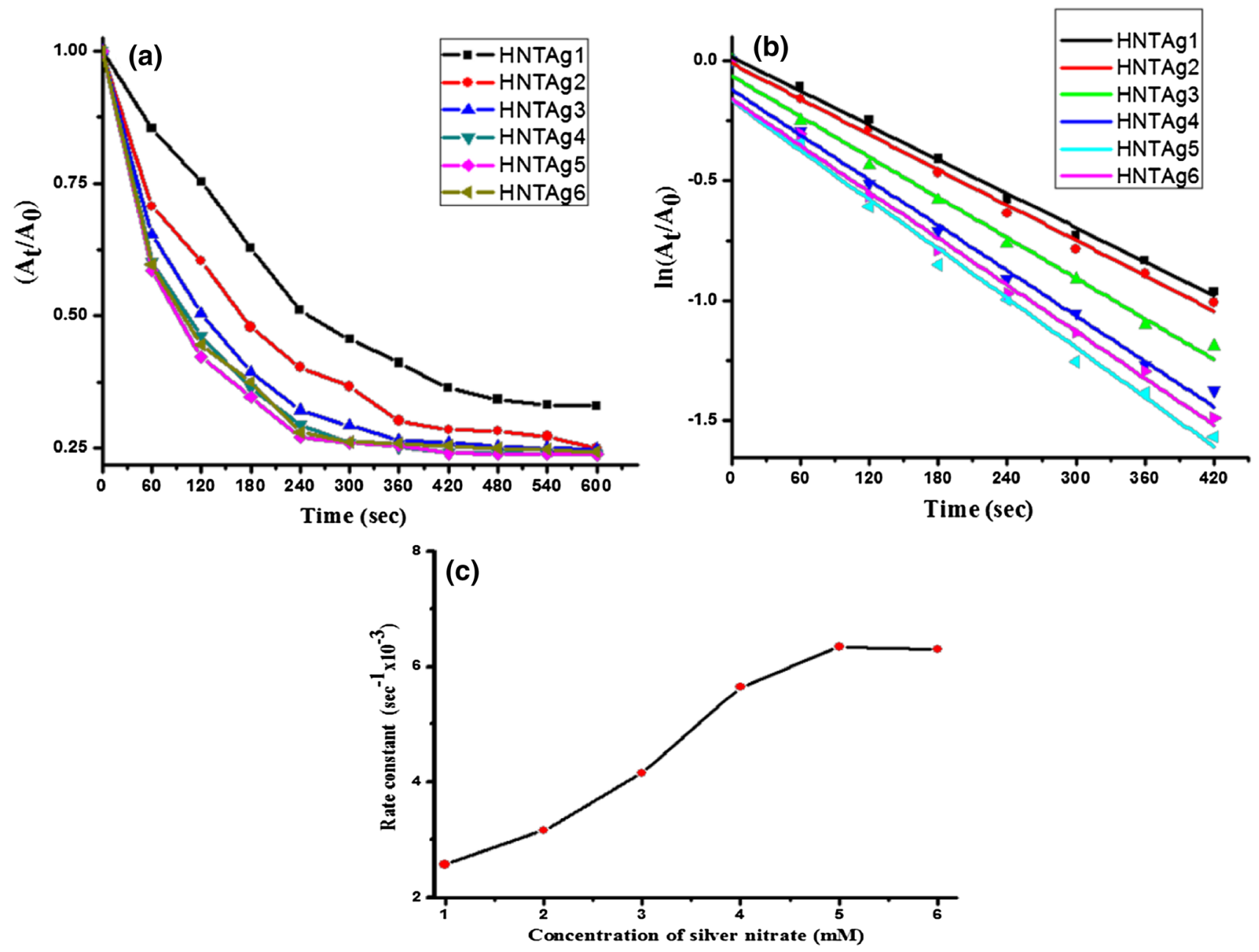

Fig. 11 a Plot of $A_{t} / A_{0}$ versus reaction time b plot of $\ln \left(A_{t} / A_{0}\right)$ versus reaction time for catalytic reduction of 4-NP in the presence of $\mathrm{NaBH}_{4}$ for different HNTAgX nanocomposite sample and $\mathbf{c}$ plot of concentration of silver nitrate versus rate constant obtained from (b)

Table 1 Obtained rate constant along with regression coefficient of different catalytic nanocomposites towards reduction of 4-NP

\begin{tabular}{lll}
\hline Nanocomposites & Rate constant $\left(\mathrm{s}^{-1}\right)$ & $\begin{array}{l}\text { R-square } \\
\text { value of liner } \\
\text { fit }\end{array}$ \\
\hline HNTAg1 & $2.57 \times 10^{-3}$ & 0.99578 \\
HNTAg2 & $3.16 \times 10^{-3}$ & 0.98953 \\
HNTAg3 & $4.45 \times 10^{-3}$ & 0.99035 \\
HNTAg4 & $5.65 \times 10^{-3}$ & 0.98466 \\
HNTAg5 & $6.35 \times 10^{-3}$ & 0.98015 \\
HNTAg6 & $6.28 \times 10^{-3}$ & 0.99123 \\
\hline
\end{tabular}

of $\mathrm{AgNO}_{3}$ and beyond this formation of aggregation takes place which reduces the rate constant to some extent. Hence, enhanced catalytic activities of the nanocatalyst indicate that the catalyst can be used in purification of water and other separation and purification from hazards 4-NP.

\section{Methylene blue degradation studies}

To investigate the diversity of as-prepared Ag/HNTs nanocatalyst, the catalytic reduction of methylene blue (MB) was also studied as model pseudo- first-order reaction due to its rapid and easy analysis (Xie et al. 2014). MB shows two characteristic UV-vis peaks at 668 and $608 \mathrm{~nm}$ due to the existing equilibrium between $\mathrm{MB}$ and its dimer (as shown in Fig. S2) (Patil et al. 2000). Reduction process could be monitored by decrease of maximum absorption peak at $668 \mathrm{~nm}$ (characteristic peak of MB) with time in UV-visible spectra and ratified by gradual change in color of the MB solution after addition of nanocatalyst and $\mathrm{NaBH}_{4}$. Without addition of nanocatalyst, mixed solution of $\mathrm{MB}$ and $\mathrm{NaBH}_{4}$ showed no noticeable color change for several hours indicating either MB cannot reduce only in the presence of $\mathrm{NaBH}_{4}$ or rate of reduction is very slow (as shown in Fig. S3). But immediately after addition of nanocatalyst, blue color of the solution disappeared within $8 \mathrm{~min}$ and finally became 
Table 2 Comparison of rate constant and time of 4-NP reduction

\begin{tabular}{lllll}
\hline Serial no. & Nanocomposites & Rate constant $\left(\mathrm{s}^{-1}\right)$ & Time & References \\
\hline 1 & Reduced GO/Pt-Ni & $1.12 \times 10^{-3}$ & $30 \mathrm{~min}$ & Sahoo et al. (2014) \\
2 & $\mathrm{Pt} @$ mesoporous alumina & $3.26 \times 10^{-3}$ & $18 \mathrm{~min}$ & Wang et al. (2015) \\
3 & $\mathrm{SiO}_{2} @$ nano-Ag & $3.56 \times 10^{-3}$ & $12 \mathrm{~min}$ & Wang et al. (2013) \\
4 & $\mathrm{Ag} / \mathrm{HLaNb} \mathrm{O}_{7}$ & $3.01 \times 10^{-3}$ & $8 \mathrm{~min}$ & Wang et al. (2012) \\
5 & $\mathrm{Ag}^{0} @ \mathrm{CMP}$ & $1.36 \times 10^{-3}$ & $60 \mathrm{~min}$ & Cao et al. (2017) \\
6 & $\mathrm{Ag}-\mathrm{Au}-\mathrm{rGO}$ & $3.47 \times 10^{-3}$ & $6 \mathrm{~min}$ & Hareesh et al. (2016) \\
7 & Our work $($ HNTAg3) & $4.45 \times 10^{-3}$ & $8 \mathrm{~min}$ & -
\end{tabular}

Italics words are used to emphasize on our results

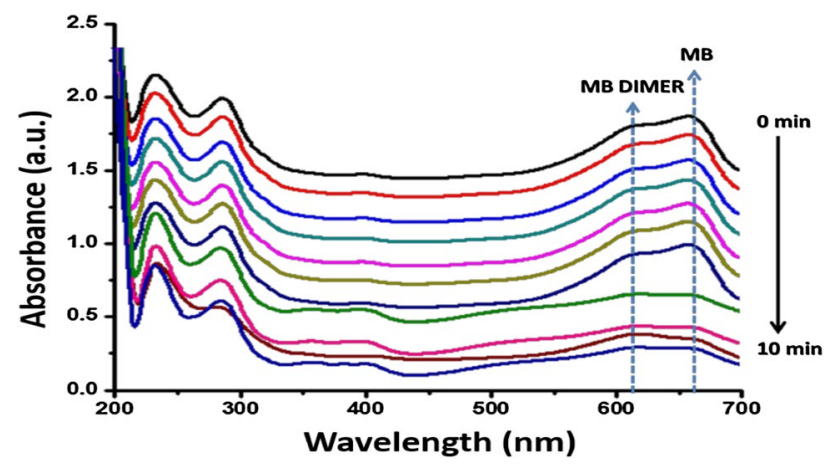

Fig. 12 Representative time-dependent UV-vis spectra of MB degradation in the presence of $\mathrm{NaBH}_{4}$ by nanocomposite

colorless indicating successful reduction of MB. Representative time-dependent UV-visible absorption spectrum of MB reduction is demonstrated in Fig. 12. It clearly exhibits that characteristic maximum absorption peak at $613 \mathrm{~nm}$ (due to MB-dimerization) and $668 \mathrm{~nm}$ (due to MB) slowly decreases with time. The result signifies the formation of leuco-methylene blue after reduction of MB by nanoctalysts (Woo and Park 2014). As the concentration of $\mathrm{NaBH}_{4}$ used in reduction reaction is higher and assumed to be remain constant, pseudo-first-order kinetic can also be applied like 4-NP reduction to determine the rate constant of the reaction. Figure 13a, b shows the plot of $\left(A_{t} / A_{0}\right)$ versus time and liner relation of plot $\ln \left(A_{t} / A_{0}\right)$ versus time which validates firstorder kinetic MB reduction in the presence of $\mathrm{NaBH}_{4}$ over nanocatalyst surface. The rate constant $(k)$ obtained from the slope of liner relation for each nanocomposites is tabulated in Table 3 which is higher than the previously published results (shown in the Table 4) (Das and Velusamy 2014; Luo
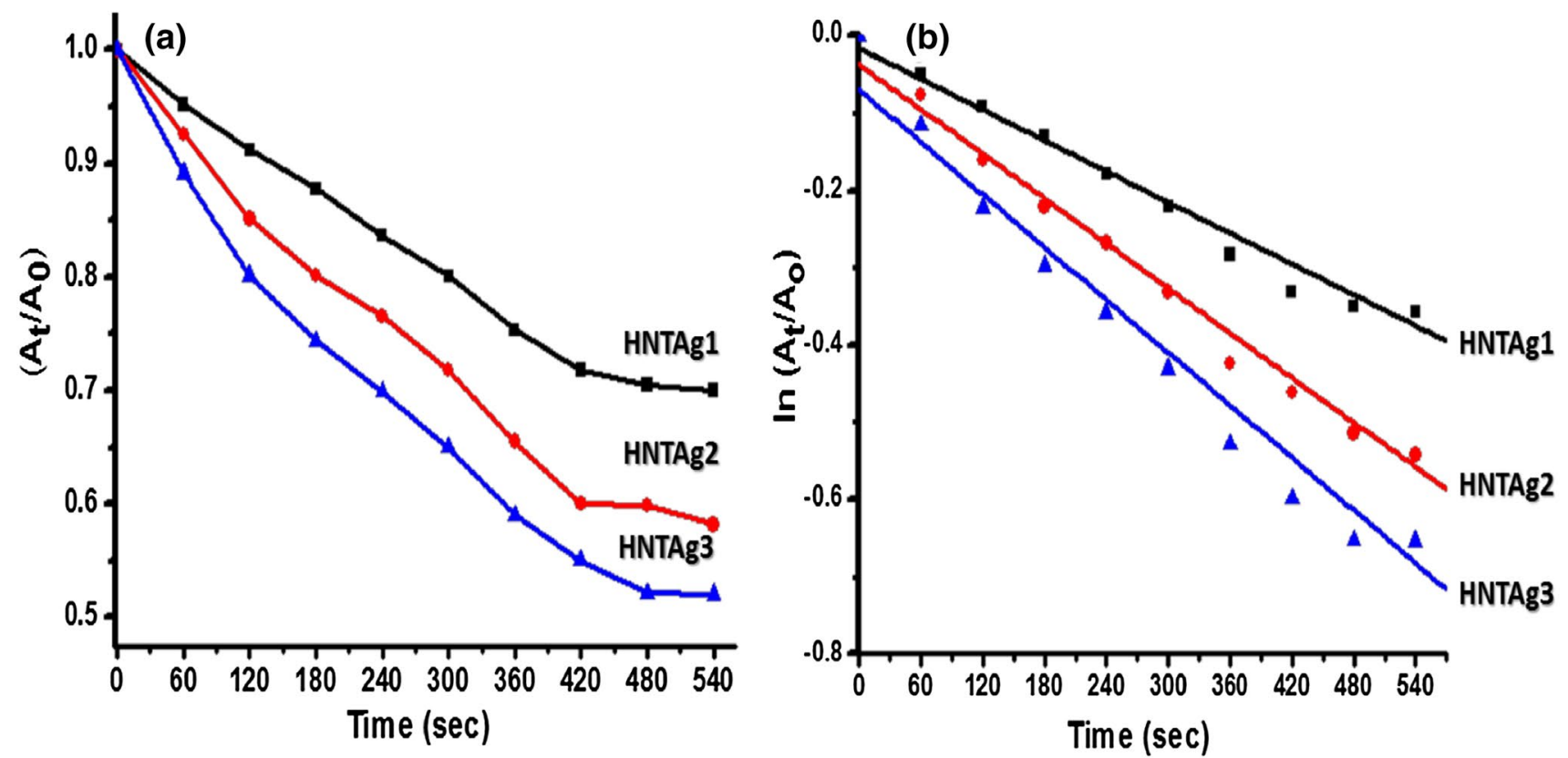

Fig. 13 a Plot of $A_{t} / A_{0}$ versus reaction time and $\mathbf{b}$ plot of $\ln \left(A_{t} / A_{0}\right)$ versus reaction time for catalytic degradation of MB in the presence of $\mathrm{NaBH}_{4}$ for different HNTAgX nanocomposite sample 
Table 3 Obtained rate constant along with regression coefficient of different catalytic nanocomposites towards reduction of $\mathrm{MB}$

\begin{tabular}{lll}
\hline Nanocomposites & Rate constant $\left(\mathrm{s}^{-1}\right)$ & $\begin{array}{l}\text { R-square } \\
\text { value of } \\
\text { liner fit }\end{array}$ \\
\hline HNTAg1 & $6.63 \times 10^{-4}$ & 0.97173 \\
HNTAg2 & $9.64 \times 10^{-4}$ & 0.96892 \\
HNTAg3 & $1.13 \times 10^{-3}$ & 0.96111 \\
\hline
\end{tabular}

et al. 2015; Patel et al. 2007; Yao et al. 2014). The distinguished catalytic activity towards MB reduction may be due to electrostatic interaction between positively charge MB molecules and negatively charged PDA molecules resulting in rapid deposition of MB molecules on the surface of the catalytic surface (Ma et al. 2015). So, catalytic activity of nanocatalyst and rate of $\mathrm{MB}$ are greatly improved.

\section{Mechanism of catalytic activity}

The catalytic reduction of 4-NP in the presence of $\mathrm{NaBH}_{4}$ on the surface of noble metal nanoparticles is considered to follow Langmuir-Hinshelwood mechanistic pathway. Figure $14 \mathrm{a}$ represents possible three steps mechanistic pathway of catalytic reduction. In the 1 st and 2 nd step both $p$-nitrophenolate ion and $\mathrm{BH}^{4-}$ are adsorbed on the surface of AgNPs decorated on the surface of HNTs. Previous studies reported that this adsorption on the surface of nanoparticles is very fast and assumed to be reversible in nature (Wunder et al. 2010). Finally in the last step, transfer of hydrogen species from $\mathrm{BH}^{4-}$ to adsorbed $p$-nitrophenolate ion the last step is the rate-determining step of the catalytic reduction and the release of 4-AP from the surface of AgNPs takes place to undergo recycle. Most important steps of catalytic reduction are shown in Fig. 14b. Introduction of AgNPs on the surface of HNTs increases the rate of catalytic reduction reaction significantly due to lower work function of $\mathrm{Ag}(4.26 \mathrm{eV})$ and
Table 4 Comparison of rate constant and time of MB degradation

\begin{tabular}{lllll}
\hline Serial no & Nanocomposites & Rate constant $\left(\mathrm{s}^{-1}\right)$ & Time & References \\
\hline 1 & $\mathrm{Au} @ \mathrm{TA}-\mathrm{GH}$ & $3.2 \times 10^{-5}$ & $9 \mathrm{~min}$ & Luo et al. (2015) \\
2 & $\mathrm{Au} @$ polypyrrole/ $\mathrm{Fe}_{3} \mathrm{O}_{4}$ & $4.6 \times 10^{-5}$ & $42 \mathrm{~min}$ & Yao et al. (2014) \\
3 & AuNPs stabilized by sesba- & $6.88 \times 10^{-4}$ & $51 \mathrm{~min}$ & Das and Velusamy (2014) \\
& nia grandiflora $\mathrm{L}$ & & \\
4 & $\mathrm{Ag} @ \mathrm{SiO}_{2}$ nanofiber & $0.05183 \times 10^{-5}$ & $8 \mathrm{~min}$ & Patel et al. (2007) \\
5 & Our work & $1.13 \times 10^{-3}$ & $10 \mathrm{~min}$ & - \\
\hline
\end{tabular}

Italics words are used to emphasize on our results
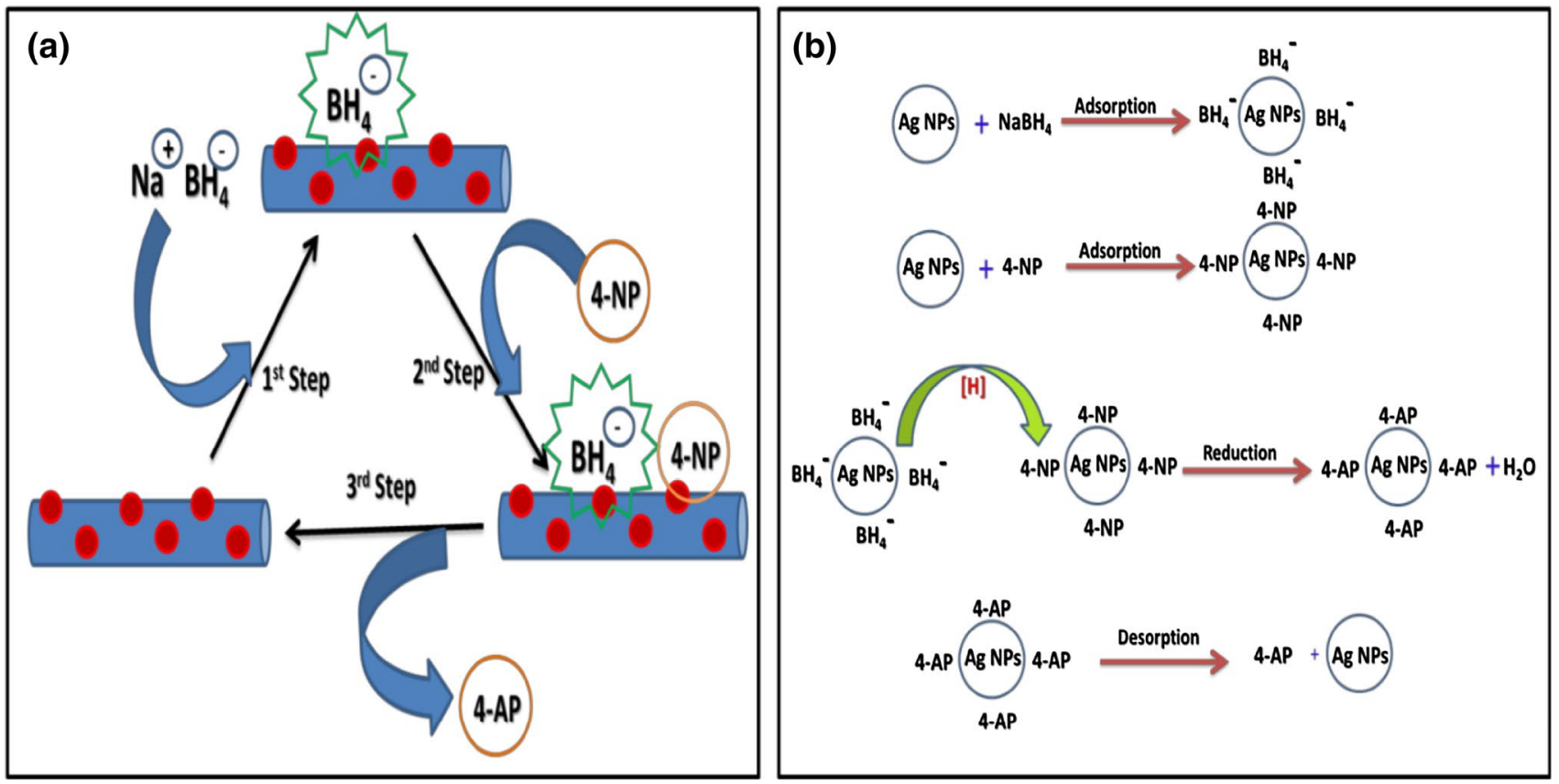

Fig. 14 a Proposed mechanism of reduction of 4-NP to 4-AP by catalytic sample and $\mathbf{b}$ schematic illustration of steps of catalytic reduction of 4-NP 
it has the tendency to release electron more easier compared to the other noble metals (Akbarzadeh et al. 2017). Though surface areas of the nanoparticles have remarkable effect on catalytic reduction, organic-inorganic hybrid structure support for AgNPs may also contribute to reduction rate by increasing adsorption ability of reactant.

\section{Reusability of the synthesized catalysts}

For practical purpose, in addition to catalytic activity reusability and stability of the nanocatlyst are other important concerns. So, these two parameters of our nanocatalyst were appraised with reduction of 4-NP and MB in the presence of $\mathrm{NaBH}_{4}$. Figure 15 shows catalytic conversion efficiency of 4-NP and MB during recycling process catalyzed by HNTAg3 nanocatalyst. The catalyst can be successfully accomplished for eight cycles maintaining conversion efficiency around $98 \%$ which signified robustness towards recycling process. The stability of the catalyst is provided by strong interaction between Ag nanoparticles and PDA layer over HNTs surface.

\section{Conclusion}

In summary, we have manifested a simple facile green way to synthesize AgNPs-decorated HNTs-supported catalytic nanocomposites using mussel inspired PDA chemistry. The firmly bounded AgNPs deposited on the surface of PDA-coated HNTs where PDA layers not only function as reducing agent but also provide stabilization for in situ synthesis of AgNPs. Synthesis of catalytic nanocomposite is very simple, rapid and environmental friendly according to the concept of green chemistry as the chemicals used for this reaction are not hazardous as well as treatment not so complicated. The HNTAgX nanocomposites show highly efficient catalytic activity towards reduction of 4-NP and

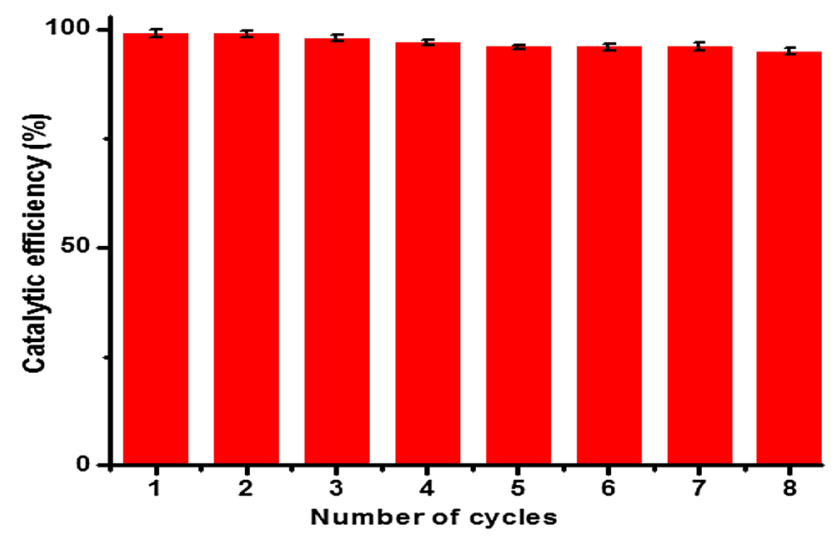

Fig. 15 Catalytic activity of nanocatalyst for reduction of 4-NP with eight times cycle use degradation of MB in the presence of very minute amount of catalytic samples. In addition to these, the catalytic samples can be reused for eight cycles without too much loss of its catalytic activity. Contemplating its simple green synthesizing process, highly efficient catalytic activity and reusability, the HNTAgX nanocomposites can be potentially applied in catalytic application, purification of wastewater and also other separation and purification fields of industrial application.

Acknowledgements This work was funded by the Science and Engineering Research Board (SERB), Department of Science and Technology (DST), Ministry of Science and Technology, Govt. of India. The Grant Number is ECR/2016/000048.

\section{References}

Akbarzadeh E, Falamarzi M, Gholami MR (2017) Synthesis of M/ $\mathrm{CuO}(\mathrm{M}=\mathrm{Ag}, \mathrm{Au})$ from $\mathrm{Cu}$ based metal organic frameworks for efficient catalytic reduction of p-nitrophenol. Mater Chem Phys 198:374-379

Almeida C, Debacher N, Downs A, Cottet L, Mello C (2009) Removal of methylene blue from colored effluents by adsorption on montmorillonite clay. J Colloïd Interface Sci 332:46-53

Annamalai J, Nallamuthu T (2016) Green synthesis of silver nanoparticles: characterization and determination of antibacterial potency. Appl Nanosci 6:259-265

Cao HL, Huang HB, Chen Z, Karadeniz B, Lü J, Cao R (2017) Ultrafine silver nanoparticles supported on a conjugated microporous polymer as high-performance nanocatalysts for nitrophenol reduction. ACS Appl Mater Interfaces 9:5231-5236

Chao C, Liu J, Wang J, Zhang Y, Zhang B, Zhang Y, Xiang X, Chen R (2013) Surface modification of halloysite nanotubes with dopamine for enzyme immobilization. ACS Appl Mater Interfaces 5:10559-10564

Choudhary MK, Kataria J, Sharma SA (2017) Biomimetic synthesis of stable gold nanoparticles derived from aqueous extract of Foeniculum vulgare seeds and evaluation of their catalytic activity. Appl Nanosci. https://doi.org/10.1007/s13204-017-0589-4

Crini G (2005) Recent developments in polysaccharide-based materials used as adsorbents in wastewater treatment. Prog Polym Sci 30:38-70

Das J, Velusamy P (2014) Catalytic reduction of methylene blue using biogenic gold nanoparticles from Sesbania grandiflora L. J Taiwan Inst Chem Eng 45:2280-2285

Das TK, Ganguly S, Bhawal P, Mondal S, Das NC (2017) A facile green synthesis of silver nanoparticle-decorated hydroxyapatite for efficient catalytic activity towards 4-nitrophenol reduction. Res Chem Intermed. https://doi.org/10.1007/s11164-017-3161-7

El Qada EN, Allen SJ, Walker GM (2008) Adsorption of basic dyes from aqueous solution onto activated carbons. Chem Eng J 135:174-184

Forgacs E, Cserhati T, Oros G (2004) Removal of synthetic dyes from wastewaters: a review. Environ Int 30:953-971

Ganguly S, Das TK, Mondal S, Das NC (2016) Synthesis of polydopamine-coated halloysite nanotube-based hydrogel for controlled release of a calcium channel blocker. RSC Adv 6:105350-105362

Ganguly S, Das P, Bose M, Das TK, Mondal S, Das AK, Das NC (2017) Sonochemical green reduction to prepare Ag nanoparticles decorated graphene sheets for catalytic performance and antibacterial application. Ultrason Sonochem 39:577588 
García MA (2011) Surface plasmons in metallic nanoparticles: fundamentals and applications. J Phys D 44:283001

GarcíaMontaño J, Ruiz N, Munoz I, Domenech X, García-Hortal JA, Torrades F, Peral J (2006) Environmental assessment of different photo-Fenton approaches for commercial reactive dye removal. J Hazard Mater 138:218-225

Golob V, Vinder A, Simonič M (2005) Efficiency of the coagulation/ flocculation method for the treatment of dyebath effluents. Dyes Pigm 67:93-97

Gong JL, Wang B, Zeng GM, Yang CP, Niu CG, Niu QY, Zhou WJ, Liang Y (2009) Removal of cationic dyes from aqueous solution using magnetic multi-wall carbon nanotube nanocomposite as adsorbent. J Hazard Mater 164:1517-1522

Gupta VK, Ali I, Saleh TA, Nayak A, Agarwal S (2012) Chemical treatment technologies for waste-water recycling-an overview. RSC Adv 2:6380-6388

Gurunathan S, Kalishwaralal K, Vaidyanathan R, Venkataraman D, Pandian SRK, Muniyandi J, Hariharan N, Eom SH (2009) Biosynthesis, purification and characterization of silver nanoparticles using Escherichia coli. Colloids Surf B 74:328-335

Hareesh K, Joshi R, Sunitha D, Bhoraskar V, Dhole S (2016) Anchoring of Ag-Au alloy nanoparticles on reduced graphene oxide sheets for the reduction of 4-nitrophenol. Appl Surf Sci 389:1050-1055

Hebbar RS, Isloor AM, Ananda K, Ismail A (2016) Fabrication of polydopamine functionalized halloysite nanotube/polyetherimide membranes for heavy metal removal. J Mater Chem A 4:764-774

Hervés P, Pérez-Lorenzo M, Liz-Marzán LM, Dzubiella J, Lu Y, Ballauff $M$ (2012) Catalysis by metallic nanoparticles in aqueous solution: model reactions. Chem Soc Rev 41:5577-5587

Holzwarth U, Gibson N (2011) The Scherrer equation versus the'Debye-Scherrer equation. Nat Nanotechnol 6:534

Hu H, Xin JH, Hu H, Wang X, Miao D, Liu Y (2015) Synthesis and stabilization of metal nanocatalysts for reduction reactions-a review. J Mater Chem A 3:11157-11182

Kang SM, You I, Cho WK, Shon HK, Lee TG, Choi IS, Karp JM, Lee H (2010) One-step modification of superhydrophobic surfaces by a mussel-inspired polymer coating. Angew Chem Int Ed 49:9401-9404

Krishna IM, Reddy GB, Veerabhadram G, Madhusudhan A (2016) Eco-friendly green synthesis of silver nanoparticles using salmalia malabarica: synthesis, characterization, antimicrobial, and catalytic activity studies. Appl Nanosci 6:681-689

Krishnaiah P, Ratnam CT, Manickam S (2017) Development of silane grafted halloysite nanotube reinforced polylactide nanocomposites for the enhancement of mechanical, thermal and dynamicmechanical properties. Appl Clay Sci 135:583-595

Ku SH, Ryu J, Hong SK, Lee H, Park CB (2010) General functionalization route for cell adhesion on non-wetting surfaces. Biomaterials 31:2535-2541

Kumar-Krishnan S, Prokhorov E, Hernández-Iturriaga M, MotaMorales JD, Vázquez-Lepe M, Kovalenko Y, Sanchez IC, LunaBárcenas G (2015) Chitosan/silver nanocomposites: synergistic antibacterial action of silver nanoparticles and silver ions. Eur Polym J 67:242-251

Küncek İ, Sener S (2010) Adsorption of methylene blue onto sonicated sepiolite from aqueous solutions. Ultrason Sonochem 17:250-257

Lee H, Dellatore SM, Miller WM, Messersmith PB (2007) Musselinspired surface chemistry for multifunctional coatings. Science 318:426-430

Lee H, Rho J, Messersmith PB (2009) Facile conjugation of biomolecules onto surfaces via mussel adhesive protein inspired coatings. Adv Mater 21:431-434

Lee BP, Messersmith PB, Israelachvili JN, Waite JH (2011) Musselinspired adhesives and coatings. Annu Rev Mater Res 41:99-132

Liu H, Wang H, Guo R, Cao X, Zhao J, Luo Y, Shen M, Zhang G, Shi X (2010) Size-controlled synthesis of dendrimer-stabilized silver nanoparticles for X-ray computed tomography imaging applications. Polym Chem 1:1677-1683

Liu H, Xi P, Xie G, Shi Y, Hou F, Huang L, Chen F, Zeng Z, Shao C, Wang J (2012) Simultaneous reduction and surface functionalization of graphene oxide for hydroxyapatite mineralization. $\mathrm{J}$ Phys Chem C 116:3334-3341

Liu Y, Ai K, Lu L (2014) Polydopamine and its derivative materials: synthesis and promising applications in energy, environmental, and biomedical fields. Chem Rev 114:5057-5115

Liu Q, Xu YR, Wang AJ, Feng JJ (2015) One-step melamine-assisted synthesis of graphene-supported AuPt@Au nanocrystals for enhanced catalytic reduction of p-nitrophenol. RSC Adv 5:96028-96033

Luo J, Zhang N, Lai J, Liu R, Liu X (2015) Tannic acid functionalized graphene hydrogel for entrapping gold nanoparticles with high catalytic performance toward dye reduction. J Hazard Mater 300:615-623

Lynge ME, Schattling P, Städler B (2015) Recent developments in poly (dopamine)-based coatings for biomedical applications. Nanomedicine 10:2725-2742

Ma A, Xie Y, Xu J, Zeng H, Xu H (2015) The significant impact of polydopamine on the catalytic performance of the carried $\mathrm{Au}$ nanoparticles. Chem Commun 51:1469-1471

Majumdar R, Bag BG, Ghosh P (2016) Mimusops elengi bark extract mediated green synthesis of gold nanoparticles and study of its catalytic activity. Appl Nanosci 6:521-528

Mohamed R, Mkhalid I, Baeissa E, Al-Rayyani M (2012) Photocatalytic degradation of methylene blue by $\mathrm{Fe} / \mathrm{ZnO} / \mathrm{SiO}_{2}$ nanoparticles under visiblelight. J Nanotechnol. https://doi. org/10.1155/2012/329082

Mu B, Wang Q, Wang A (2013) Preparation of magnetic attapulgite nanocomposite for the adsorption of $\mathrm{Ag}+$ and application for catalytic reduction of 4-nitrophenol. J Mater Chem A 1:7083-7090

Pasbakhsh P, Churchman GJ, Keeling JL (2013) Characterisation of properties of various halloysites relevant to their use as nanotubes and microfibre fillers. Appl Clay Sci 74:47-57

Patel AC, Li S, Wang C, Zhang W, Wei Y (2007) Electrospinning of porous silica nanofibers containing silver nanoparticles for catalytic applications. Chem Mater 19:1231-1238

Patil K, Pawar R, Talap P (2000) Self-aggregation of methylene blue in aqueous medium and aqueous solutions of $\mathrm{Bu} 4 \mathrm{NBr}$ and urea. Phys Chem Chem Phys 2:4313-4317

Raza A, Javed S, Qureshi MZ, Khan MS (2017) Synthesis and study of catalytic application of L-methionine protected gold nanoparticles. Appl Nanosci. https://doi.org/10.1007/s13204-017-0587-6

Robinson T, McMullan G, Marchant R, Nigam P (2001) Remediation of dyes in textile effluent: a critical review on current treatment technologies with a proposed alternative. Bioresour Technol 77:247-255

Sahoo PK, Panigrahy B, Bahadur D (2014) Facile synthesis of reduced graphene oxide/Pt-Ni nanocatalysts: their magnetic and catalytic properties. RSC Adv 4:48563-48571

Sobczak-Kupiec A, Malina D, Wzorek Z, Zimowska M (2011) Influence of silver nitrate concentration on the properties of silver nanoparticles. Micro Nano Lett 6:656-660

Venkatesham M, Ayodhya D, Madhusudhan A, Babu NV, Veerabhadram G (2014) A novel green one-step synthesis of silver nanoparticles using chitosan: catalytic activity and antimicrobial studies. Appl Nanosci 4:113-119

Wang C, Tang K, Wang D, Liu Z, Wang L (2012) Simple self-assembly of HLaNb $2 \mathrm{O} 7$ nanosheets and Ag nanoparticles/clusters and their catalytic properties. J Mater Chem 22:22929-22934

Wang M, Tian D, Tian P, Yuan L (2013) Synthesis of micron-SiO $\mathrm{S}_{2}$ nano-Ag particles and their catalytic performance in 4-nitrophenol reduction. Appl Surf Sci 283:389-395

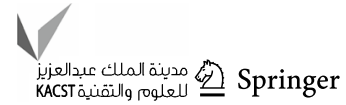


Wang Q, Zhang Y, Zhou Y, Zhang Z, Xu Y, Zhang C, Sheng X (2015) Synthesis of dendrimer-templated Pt nanoparticles immobilized on mesoporous alumina for p-nitrophenol reduction. New J Chem 39:9942-9950

Wang Z, Xie Y, Li Y, Huang Y, Parent LR, Ditri T, Zang N, Rinehart JD, Gianneschi NC (2017) Tunable, metal-loaded polydopamine nanoparticles analyzed by magnetometry. Chem Mater 29:8195-8201

Woo H, Park KH (2014) Hybrid Au nanoparticles on $\mathrm{Fe}_{3} \mathrm{O}_{4} @$ polymer as efficient catalyst for reduction of 4-nitrophenol. Catal Commun 46:133-137

Wunder S, Polzer F, Lu Y, Mei Y, Ballauff M (2010) Kinetic analysis of catalytic reduction of 4-nitrophenol by metallic nanoparticles immobilized in spherical polyelectrolyte brushes. J Phys Chem C 114:8814-8820

Xie Y, Yan B, Xu H, Chen J, Liu Q, Deng Y, Zeng H (2014) Highly regenerable mussel-inspired $\mathrm{Fe}_{3} \mathrm{O}_{4} @$ polydopamine-Ag coreshell microspheres as catalyst and adsorbent for methylene blue removal. ACS Appl Mater Interfaces 6:8845-8852

Yao T, Cui T, Wang H, Xu L, Cui F, Wu J (2014) A simple way to prepare $\mathrm{Au} @$ polypyrrole/ $/ \mathrm{Fe}_{3} \mathrm{O}_{4}$ hollow capsules with high stability and their application in catalytic reduction of methylene blue dye. Nanoscale 6:7666-7674

Zeng T, Niu HY, Ma YR, Li WH, Cai YQ (2013) In situ growth of gold nanoparticles onto polydopamine-encapsulated magnetic microspheres for catalytic reduction of nitrobenzene. Appl Catal B 134:26-33

Zhai R, Zhang B, Liu L, Xie Y, Zhang H, Liu J (2010) Immobilization of enzyme biocatalyst on natural halloysite nanotubes. Catal Commun 12:259-263

Zhang Y, Yang H (2012) Halloysite nanotubes coated with magnetic nanoparticles. Appl Clay Sci 56:97-102

Zhang Y, Chen Y, Zhang H, Zhang B, Liu J (2013) Potent antibacterial activity of a novel silver nanoparticle-halloysite nanotube nanocomposite powder. J Inorg Biochem 118:59-64

Zhao M, Liu P (2008) Adsorption behavior of methylene blue on halloysite nanotubes. Microporous Mesoporous Mater 112:419-424

Zhong S, Zhou C, Zhang X, Zhou H, Li H, Zhu X, Wang Y (2014) A novel molecularly imprinted material based on magnetic halloysite nanotubes for rapid enrichment of 2,4-dichlorophenoxyacetic acid in water. J Hazard Mater 276:58-65

Zia F, Ghafoor N, Iqbal M, Mehboob S (2016) Green synthesis and characterization of silver nanoparticles using Cydonia oblong seed extract. Appl Nanosci 6:1023-1029

Publisher's Note Springer Nature remains neutral with regard to jurisdictional claims in published maps and institutional affiliations. 